\title{
Regulation Conditions Influence on the Thermic and Exergic Efficiency Factors Size with the Heat Exchanger of a Coiled Type
}

\author{
Trofymchuk Oleksandr, Oleksiuk Anatoliy and Shytikova Irina \\ Institute of Telecommunications and Global Information Space, National Academy of Sciences of Ukraine, Kiev 03680, Ukraine
}

Received: March 17, 2016 / Accepted: March 31, 2016 / Published: May 31, 2016.

\begin{abstract}
The thermal engineering research has been executed for the threecircuit heat exchanger of a coiled type, that provides the thermal loads regulation for the heating and hot water supply systems. A processing curve of the warmth supply regulation at a combined heating and hot water supply load, was used at that. It is important to know the processes running inside the apparatus for the technical characteristics improvement of the threecircuit heat exchanger of a coiled type. The task solution will allow save the materials consumption for the threecircuit heat exchangers of a coiled type manufacturing in the future.
\end{abstract}

Key words: Heating-accumulating unit, threecircuit heat exchanger, independent heating supply system.

\section{Decision Problem}

The fuel-energy complex research has allowed to disclose a huge power-saving potential in the municipal heat-and-power engineering [1]. Power-and-resource-saving units and systems get a special urgency in the realization of this potential in connection with the power engineering crisis expansion. While changing the main controlled parameters and factors, one can obtain a considerable increase of the exploitation efficiency and optimization of heat exchanger as well as the heating supply system in total [2].

2. The Latest Research and Publications Analysis

The questions of the heating device mathematical pattern creation were discussed in many authors' works. A series of functional relations, the constituent parameters of which can be known by the apparent way

Corresponding author: Trofymchuk Oleksandr, doctor of technical sciences, professor, research fields: mathematical modeling and energy saving in heating systems. or can be defined taking into consideration some assumptions, is assigned [3]. The heating exchanging device construction was calculated and the intensification processes were considered in previous works. The units choice calculation was developed at the analytical research and engineering methods of the heating exchanging devices investigation $[4,5]$.

\section{Objectives}

The scientific foundation and development of the heating exchanging devices for the independent heating and hot water supply system construction efficient resolutions, calculation and choice of the reasonable constructive variant are the objectives of the work.

\section{The Basic Material}

According to the curve, the basic parameters of the heating thermofor have been defined subject to the outside air temperature change at regular intervals, that has influenced the size of the thermic efficiency factoras well, as the exergic one during the whole heating period and even in summer as far as the hot water supply system works all the year round $[6,7]$. 


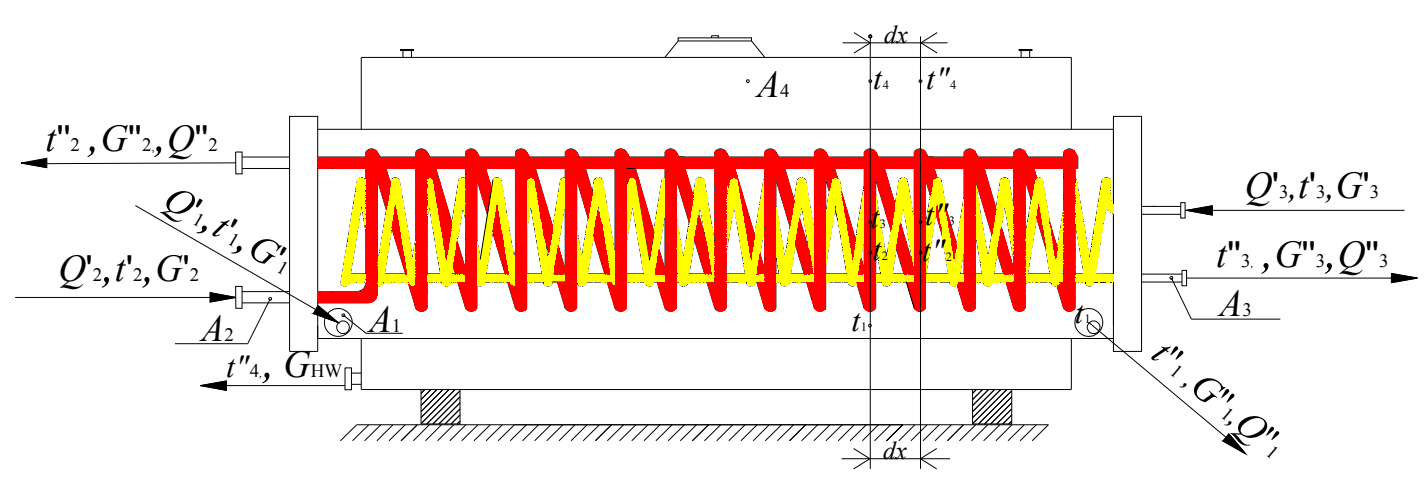

Fig. 1 Scheme of the heating-accumulating unit dismountable construction with the heat exchanger of a coiled type.

The primary heat-carrier $\tau_{1}, \tau_{2}$, the secondary heat-carriers for the heating $t_{10}$ and $t_{20}$, and hot water supply systems $t_{h}$ and $t_{c}$ temperatures, that have been limited to the outside air temperature $t_{o}$, have served as the fundamental calculating data. The change of the primary heat-carrier capacity $G_{H}^{1}, G_{H W S}^{1}$ and $G$ for the heating and hot water supply at the permanent capacities of the secondary (heating) heat-carriers $G_{H}^{1}$, $G_{H W S}^{1}$ for the same systems has been issued proportionally to the changes of the temperature pressures of the primary heat-carrier as well as the secondary ones (Fig. 1).

The threecircuit heat exchanger work efficiency evaluation has been carried out by the comparison of the thermic $\eta_{t}$ and exergic $\eta_{e}$ efficiency factors quantities, with the quantities $\eta_{t}{ }^{\prime}, \eta_{e}{ }^{\prime}$ for the heating system and also for the hot water supply system $\eta_{t}{ }^{\prime \prime}, \eta_{e}{ }^{\prime \prime}$ by means of two rapid water-heaters, that accomplish the same task as one threecircuit heat exchanger of a coiled type does.

Two equal systems, that help to achieve the formulated object, are discussed at that. The heat carrier parameters in the node point are defined for equal thermal loads on heating and hot water supply according to the processing curve of regulation in heating-accumulating unit, with threecircuit heat exchanger of a coiled type and two rapid heat exchangers working under the same conditions.

The data depending on the outside air temperature and the accepted curve of regulation where $\tau=f\left(t_{H}\right)$ and $\sum \tau=f\left(t_{H}\right)$. The qualitative regulation of the warmth supply for the heating and local quantitative, one for the load of the hot water supply at the warmth source are carried out over the range outside air temperatures from $t_{H O}=-23{ }^{\circ} \mathrm{C}$ till $t_{H}{ }^{\prime \prime}=1.6{ }^{\circ} \mathrm{C}$. As for the consumption of the heating thermofors $G_{H}^{1}, G_{H W S}^{1}$ they keep constant (Fig. 2).

The comparative analysis of the heat exchanging efficiency in a threecircuit heat exchanger of a colied type in comparison to the rapid ones, at the equal consumption of the heat carrier in local heating, and hot water supply systems has been conducted for visual clarity. The magnitudes of thermic and exergic efficiency factors for threecircuit heat exchanger and the summarized magnitudes for the regular rapid ones, produced by the industry, are shown in Fig. 3. The character of the curve conduct for the thermic efficiency factor as well as for the exergic one in these heat-exchanging devices are approximately equal, but it differs in the absolute magnitude in favour of the threecircuit heat exchanger. The exergic efficiency factor curves have some burst for the increase, that is explained by the increase of the consumption of the heating thermofor in the salient point of the processing curve $t_{H}=1.6{ }^{\circ} \mathrm{C}$, at transfer from the qualitative regulation to the local quantitative one, and then gradual decrease to $t_{H}=+8{ }^{\circ} \mathrm{C}$, that meets the beginning of the heating period. Only hot water supply load takes place in summer period, but the exergic efficiency factor continues to recede because of the exergy losts increase in the contour of the hot water supply system, as far as the temperature drop of the heating thermofor keeps 


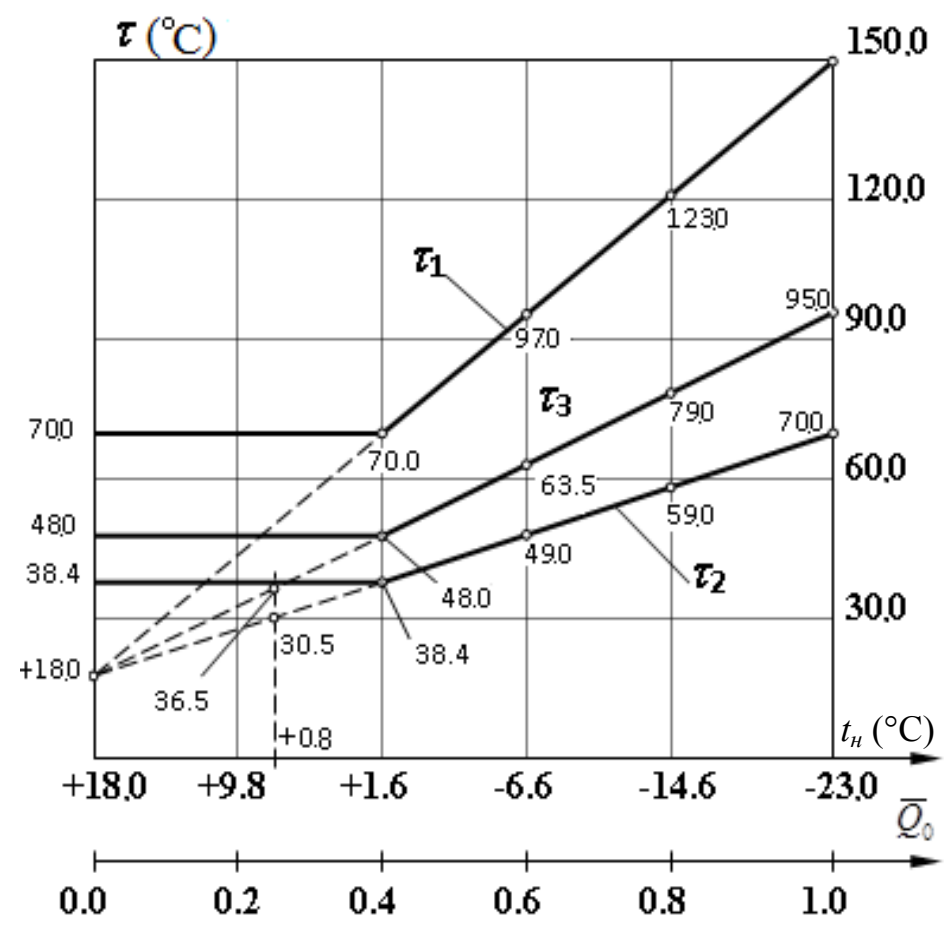

Fig. 2 Processing curve of the warmth supply regulation at the combined heating and hot water supply load.

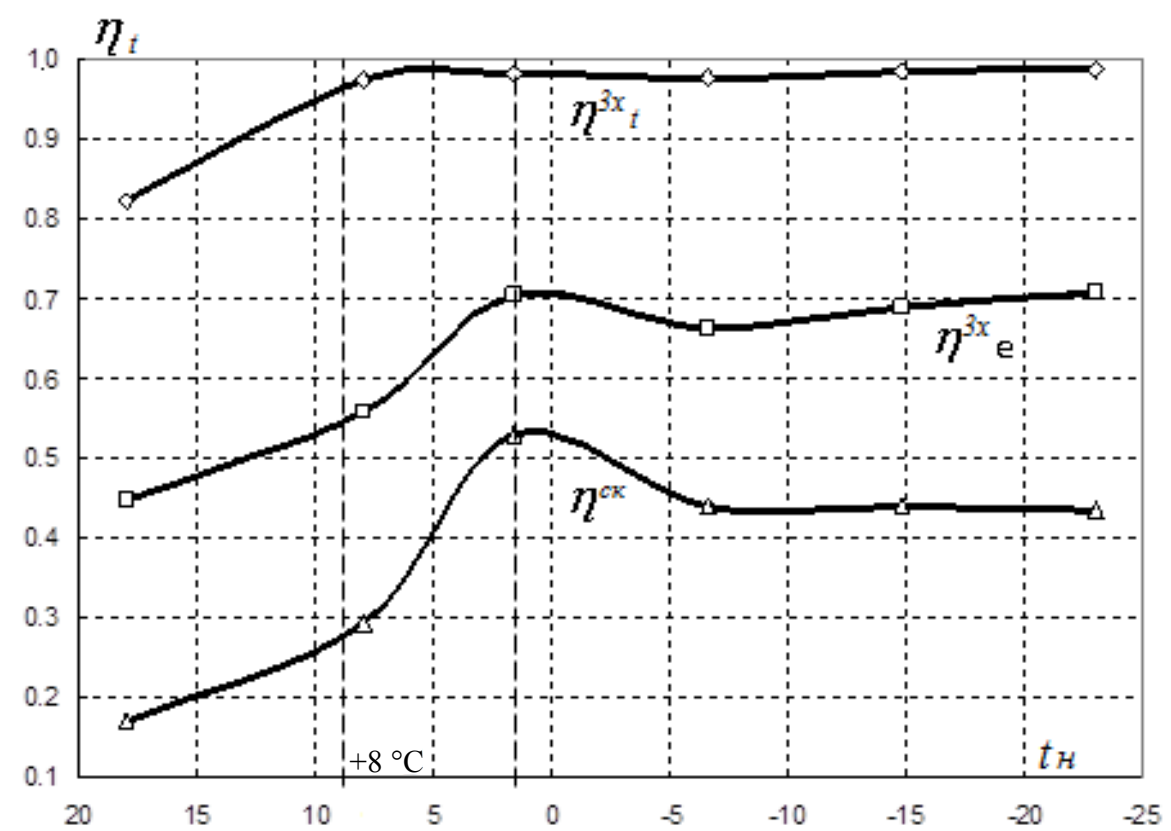

Fig. 3 Comparison of thermic and exergic efficiency factors of the threecircuit heat exchanger of a coiled type with the rapid ones depending on the conditions of the warmth supply regulations.

constant, and the temperature drop of the heated water reduces at the expence of the cold water-pipe water $t_{x . n}$ temperature increase in the summer period at the entry of heat exchanger.
Comparison of the effectiveness of the threecircuit heat exchangers of a coiled type work with the help of exergic and thermodynamic analisys, allows to present visually the appropriateness of the threecircuit heat 
exchanger of a coiled type for the independent heating and hot water supply systems at independent heating unit with heating-accumulating unit use.

The processing of the results of the threecircuit heat exchangers of a coiled type research has been conducted at the computer. The exergic efficiency factor $\eta_{e}=\frac{\sum E^{\prime \prime}}{\sum E^{\prime}}$ serves as the objective function at the thermodynamic optimization, as far as it reflects directly thermodynamic unimprovability of the engineering system, the correct calculation of the objective function is possible only in view of compilinig of the exergic balance, on basis of which the unified exergic indicator is defined- $\eta_{e}$, the system efficiency factor changing depends mostly on its mode of operation, where the outside air temperature, expenditures and calculated temperatures of the primary and secondary heat carriers for the heating and hot water supply systems serve as the main parameters.

Using the statistical valuation of the results of the regression equation coefficients and correlation coefficients, thermic efficiency factor $\eta_{t}$ is characterized with the equation:

$$
\begin{gathered}
\eta_{t}=-856+12.9 T_{H}-0.072 T_{H}{ }^{2}+0.00018 T_{H}{ }^{3}-1.69 \\
\times 10^{-7} T_{H}{ }^{4}
\end{gathered}
$$

where, $T_{o}$ is the outside air temperature, $\mathrm{K}$.

The valuation of the statistical relevancy of the regression equations and conformity equations coefficients is verified with the Fischer criterion [1]:

$$
F=S^{2} / S_{o c m}^{2}
$$

where, $\quad S^{2}=\frac{\sum y^{2}-\left(\frac{1}{n}\right)\left(\sum y\right)^{2}}{n-1}$ is the mean-square deviation, compiles $S_{\text {ocm }}^{2}=\frac{\sum(y-\hat{y})^{2}}{n-2}$ is the remanent mean-square deviation.

We check the equation conformity by the Fischer criterion.

The table quantity of the Fischer criterion for the threecircuit heat exchanger of a coiled type is:

$F_{3 \text { circ. }}=0.695$, for rapid $-F_{\text {rap. }}=4.77$.

Exergic efficiency factor $\eta^{3 x}$ for the threecircuit heat exchanger of a coiled type is described with the empirical equation of the third degree:

$$
\eta^{3 x}{ }_{e}=428-4.89 T_{H}+0.019 T_{H}^{2}-2.36 \times 10^{-5} T_{H}^{3}(3)
$$

and the exergicefficieny factor for the rapid heat exchangers is:

$$
\eta_{e}^{\text {speed }}=869-9.95 T_{H}+0.0379 T_{H}^{2}-4.819 \times 10^{-6} T_{H}{ }^{3}
$$

The table quantities of the Fischer criterion [8] argue that, the derived regression equations are significant at the 0.05 percent degree $(99.95 \%$ of the confident probability).

The received empirical formulae allows to optimize the thermic and exergic efficiency factors quantities, that allows to increase the effectiveness of the threecircuit heat exchangers of a coiled type for the heating and hot water supply systems from at independent heating unit with heating-accumulating unit heat exchange.

\section{Conclusions}

The received results can be used while developing the recommendations on the increase of the exergic effectiveness of the threecircuit heat exchangers of a coiled type for heating-accumulating unit, that are installed on the independent heating unit of the serial production. The exergic efficiency factor calculation method will allow to give the qualitative valuation for newly projectible heat exchanging devices of a coiled type, in which the exergic efficiency factor is higher within the limits of $22.70 \%-38.67 \%$.

Using the exergic calculation of the system method, one can define more precisely the exergic efficiency factor of any heat exchanging device.

\section{References}

[1] Oleksiuk, A. A. 2009. "Energy-and-Resource-Saving Heating Supply Systems with the Individual Heating Points and Multicircuit Heat Exchangers." Doctor of science degree competition dissertation, Donbas National 

with the Heat Exchanger of a Coiled Type

Academy of Civil Engineering and Architecture.

[2] Oleksyuk, A. A., and Shitikova, S. G. 2013. IPC F24D $11 / 00 /$ begutachtung heat exchanger smog type for independent systems of heating and hot water supply. Ukraine Patent 81,831, filed April 2, 2013, and issued October 7, 2013.

[3] Denisenko, Y. 2008. "Heating Unit Mathematical Pattern Structural Identification Objective Solution." SyuSU Herald 26 (10): 4-9.

[4] Shitikova, G. I. 2014. "Influence of Regulation Modes on the Thermic and Exergic Efficiency Factors Magnitude in the Heat Exchanger of a Coiled Type." Interdepartmental Scientific and Technical Collection "Constructional Industry" 57 (2): 46-51.

[5] Shitikova, G. I. 2014. "Heat Exchange in the Heat
Exchanger of a Coiled Type for the Independent Heating and Hot Water Supply Systems Simulation." Donbas National Academy of Civil Engineering and Architecture Herald 5 (109): 68-72.

[6] Sadawarte Y. A., and Hiware, T. 2012. "Non Conventional Sources of Energy." In Proceedings of the International Conference on Emerging Frontiers Technology, 8.

[7] Aronson, K. E. 2003. "Heat Exchangers of Power Plants." In Textbook for High Schools, edited by Aronson, K. E., Blinkov, S. N., and Brezgin, V. I. Ekaterinburg: Sokrat, 968.

[8] Samarskii A. A., and Vabishchevich P. N. 2003. Computational Heat Transfer. Moscow: Editorial URSS, 784. 